\section{Food and development}

The Nutrition Factor: A Stuay jointly by the Foundation for Child Development and the Brookings Institution. By Alan Berg. Portions with Robert J. Muscat. Pp. xii +299 . (Brookings Institution: Washington DC; Allen and Unwin: London, August 1973.) $£ 4.50$ boards; $£ 1.75$ paper.

THIS is a worthwhile book. It is concerned with the improvement of nutritional health in the developing countries but differs from most other books on the subject in that it goes to great length to point out that such improvements have an important role in national development. This is not a practical manual in that it does not set out stepby-step instructions - the approach is not so dogmatic; rather it deals in a philosophical way with the background to the problem and suggests principles for effecting change. The book will surely become essential reading for students of applied nutrition and for those administrators and civil servants in the developing countries who have need to convince their rulers that the malnourished members of the community are not economically insignificant.

The starting point of Dr Berg's philosophy is best summed up in his own words: "malnutrition adversely affects mental development, physical development, productivity, the span of working years-all of which significantly influence the economic potential of man". It would be easy to quibble with the opening chapters in which Dr Berg justifies this statement. Perhaps too little theoretical proof is available but few scientists or doctors would doubt its basic truth, and the aim of the book is to encourage national action rather than stimulate further fundamental research.

A whole chapter is devoted to the cynical but often encountered argument that improved nutrition will merely exacerbate the population problem. The nutritional adviser will need to combat this line of attack; the chapter provides some valuable ammunition. People in developing countries will not readily accept contraception until they can be sure that their children, in particular sons, will survive.

Dr Berg quite rightly believes that significant nutritional improvements at a community level will materialise only if the problem is viewed from a national perspective and tackled by broadly based preventive measures. $\mathrm{He}$ points out the limitations of the "person to person diagnostic and curative approach"; however essential this may be to the ministries of health, national planners need to adopt a more comprehensive policy. The main possibilities discussed are: economic growth leading to higher incomes and hence better nutrition, improved agricultural production and farming technology, nutritional education, the formulation of new foods and nutrient fortification, the encouragement of new food industries and, finally, feeding children through nationally organised public programmes. Each topic is dealt with and commented on in an instructive manner. The conclusion is that each approach has its valuable features but none can achieve the desired goal alone; an integrated plan is essential.

The main stimulus for Dr Berg's approach to malnutrition has been his experience of India, and the narrative ends with a discussion of the lessons learnt there both from the general situation and from the crisis brought about by the Behar famine. Dr Berg considers that the beginnings of a national programme in India can be looked upon as a prototype by other nations.

The book concludes with numerous tables and appendices providing valuable facts and figures together with a comprehensive bibliography.

This monograph purposefully confines itself to the food and dietary

\section{Solid state electrochemistry}

Electrochemistry of Metals and Semiconductors: The Application of Solid State Science to Electrochemical Phenomena. By Ashok K. Vijh. Pp. xiv +297 . (Dekker: New York, May 1973.) $\$ 23.50$.

THE electrode-solution interface has been studied from the viewpoint of solid state physics by many workers since the pioneer paper of Grimley and Mott in the 1947 Faraday Discussion. During these years the theory of redox reactions at metal or semiconductor electrodes has been developed by Gerischer on the basis of the classical hydrogen overvoltage paper of R. W. Gurney; a good many practical applications have been examined, and some established in industry. Dr Vijh works in the Hydro-Quebec Institute of Research, and has published a number of papers in recent years. His book sets out to provide first a rudimentary introduction to the solid state (really band theory) to electrochemists unfamiliar with this topic. There follow eight chapters, including three on electrode reactions (general principles, elemental semiconductors, bulk compound semiconductors), then anodic oxidation of metals and non metals, and the effect of surface films on electrode reactions. In chapter 7 the solid state properties of metals are related to their electrochemical behaviour, and in chapter 8 electrochemistry in the solid state (as solid electrolytes and proton factors involved in malnutrition and readers might, if they did not read carefully the penultimate paragraph of the first chapter, be led to believe that these were the only ones that matter. Perhaps it is of value to dispel this idea by again quoting Dr Berg: "In a systematically planned search for remedies to nutritional problems, many non-standard nutritional measures will be considered. Protected water supplies, waste disposal and other forms of environmental sanitation, immunisation against certain diseases, for instance, all relate to the incidence of malnutrition, its relative severity and the reduction of mortality. Although such measures are not normally thought of as nutritional measures, they may be significant determinants of nutritional status, or, more likely, essential in combination with the food-related measures that this study focuses on".

These words emphasise still further the enormity of the problem facing those who are trying to improve nutritional health in the developing world. Little wonder Dr Berg advocates such far-reaching preventive measures; his book is timely and warmly welcomed.

R. G. WhiteHEAD

conduction in ice, and so on) is studied A final chapter deals with industrial aspects, some ten applications being noted from fuel cells and batteries to mineral processing.

Most of my criticisms turn on points of detail, since the book as a whole usefully fills an important gap in the monographic literature. To say that semiconductors show a non-Ohmic behaviour under ordinary conditions (p. 21) is surely rather misleading. In view of its importance more attention should have been given to explaining the Fermi level, and its relation to energy bands and impurity levels. The printing of the various Galvani potentials on p. 191 et seq. leaves much to be desired. On p. 21 intrinsic conductivity is rightly written as $\sigma_{0} \exp -\left(E_{z} / 2 k T\right)$, on p. 131 wrongly as $\sigma_{0} \exp -\left(E_{\mathrm{g}} / k T\right)$. There is published evidence for the free energy of activation for oxide growth proportional to the oxide thickness (p. 132) but this is not quoted.

Putting such detailed matters on one side, the book is easy to read, and should perform a valuable function in introducing research workers to an important new field of interfacial activity, and we may expect it to stimulate further efforts in this direction. Biological systems are rightly excluded from the present volume, but there are also signs of a growing activity in this area.

D. D. ELEY 